\title{
Inhaltsverzeichnis Table of Contents
}

ALEX BURRI
Einleitung: Zwischen Sprache und Denken $\ldots \ldots \ldots \ldots \ldots \ldots \ldots$
PETER SIMONS
Linearity and Structure. Notes on the Discrepancy between Speaking and

Thinking ....................... 30

DANIEL C. DENNETT

The Role of Language in Intelligence . . . . . . . . . . . . . . . . . . 42

KATIA SAPORITI

Die Fiktion einer Sprache des Geistes in der zeitgenössischen Philosophie 56

ANSGAR BECKERMANN

Ist eine Sprache des Geistes möglich? . . . . . . . . . . . 75

WOLFGANG LENZEN

Searles chinesischer Zauber oder Wahrnehmung, Sprachverständnis und

der Turing-Test $\ldots \ldots \ldots \ldots \ldots$. . . . . . . . . . . 93

MICHAEL DEVITT

On Determining Reference . . . . . . . . . . . . . . . . . 112

KEVIN MULLIGAN

How Perception Fixes Reference . . . . . . . . . . . . . . . . . . . 122

KUNO LORENZ

Rede zwischen Aktion und Kognition . . . . . . . . . . . . . . . . . . 139

THOMAS RUPRECHT

Die kausale Relevanz des Geistigen . . . . . . . . . . . . . . . . . 157

JAY F. ROSENBERG

Kantian Schemata and the Unity of Perception . . . . . . . . . . . 175

GÉRARD BORNET

Der sichtbare Geist. Sprache und Denken in Booles Philosophie der Logik 190 
DIETER MÜNCH

Intention und Kognition . . . . . . . . . . . . . . . . . . . 214

ANDREAS KEMMERLING

Zur sog. Naturalisierung von Intentionalität . . . . . . . . . . . . 237

DAVID M. ROSENTHAL

Thinking that One Thinks . . . . . . . . . . . . . . . . . . . 259

FRED DRETSKE

The Nature of Thought $\ldots \ldots \ldots \ldots \ldots \ldots \ldots$

JOSEF SEIFERT

Sprache und Wahrheit. Zum Verhältnis zwischen Satz, Urteil und

Sachverhalt . . . . . . . . . . . . . . . . . . . . . . . . 301

ANDREAS KAMLAH

Anschauliches und symbolisches Denken $\ldots \ldots \ldots \ldots \ldots \ldots$

GOTTFRIED GABRIEL

Logisches und analogisches Denken. Zum Verhältnis von

wissenschaftlicher und ästhetischer Weltauffassung . . . . . . . . . 370 